\title{
Association of Early Inhaled Nitric Oxide With the Survival of Preterm Neonates With Pulmonary Hypoplasia
}

Kevin R. Ellsworth, MD; Marc A. Ellsworth, MD; Amy L. Weaver, MS; Kristin C. Mara, MS; Reese H. Clark, MD; William A. Carey, MD

IMPORTANCE Pulmonary hypoplasia affects a very small percentage of preterm neonates, but its presence is associated with high rates of mortality.

OBJECTIVE To determine whether treatment with inhaled nitric oxide during the first week of life was associated with improved in-hospital survival in a cohort of extremely preterm neonates with pulmonary hypoplasia.

DESIGN, SETTING, AND PARTICIPANTS This cohort study used data from the Pediatrix Medical Group's Clinical Data Warehouse, a data set containing information from more than 350 neonatal intensive care units in 35 US states and Puerto Rico. Since inhaled nitric oxide was not randomly prescribed, we used 1-to-1 propensity score matching to reduce the imbalance of measured covariates between the 2 treatment groups. The initial, unmatched cohort included singleton neonates who were born between 22 and 29 weeks' gestation, had a birth weight of $400 \mathrm{~g}$ or more, were diagnosed with pulmonary hypoplasia as a cause of their respiratory distress, remained free of major anomalies, and were discharged between January 1, 2000, and December 31, 2014. We defined exposure as the initiation of inhaled nitric oxide on day $t$ in days 0 to 7 of the life of a neonate. Each exposed neonate was matched 1-to-1 to a neonate who had not initiated inhaled nitric oxide on a given day.

MAIN OUTCOMES AND MEASURES The primary outcome was mortality defined as death prior to transfer or discharge home. Secondary outcomes were any-stage necrotizing enterocolitis, retinopathy of prematurity requiring treatment, chronic lung disease, and periventricular leukomalacia.

RESULTS Among 92635 neonates in our study sample, we identified $767(0.8 \%)$ with pulmonary hypoplasia who met all study inclusion criteria, of whom $185(0.2 \%)$ were exposed to inhaled nitric oxide. Among 151 matched pairs of exposed and unexposed neonates, we did not identify a significant association between inhaled nitric oxide use and mortality (hazard ratio [HR], 0.79; $95 \% \mathrm{Cl}, 0.57-1.11)$. Subgroup analyses of neonates with and without persistent pulmonary hypertension (PPHN) likewise revealed no significant association between inhaled nitric oxide use and mortality (pulmonary hypoplasia with PPHN: HR, 0.67; 95\% Cl, 0.45-1.01; pulmonary hypoplasia without PPHN: $\mathrm{HR}, 1.11 ; 95 \% \mathrm{Cl}, 0.61-2.02$ ), but these findings may have been influenced by ascertainment bias.

CONCLUSIONS AND RELEVANCE Early treatment with inhaled nitric oxide is not associated with improved survival among extremely preterm neonates with pulmonary hypoplasia. Clinical trials are warranted to clarify the matter.

JAMA Pediatr. 2018;172(7):e180761. doi:10.1001/jamapediatrics.2018.0761

Published online May 7, 2018.
Supplemental content

Author Affiliations: Division of Neonatal Medicine, Mayo Clinic, Rochester, Minnesota (K. R. Ellsworth, Carey); Department of Child Health, University of Arizona, Phoenix (M. A. Ellsworth);

Department of Health Sciences Research, Mayo Clinic, Rochester, Minnesota (Weaver, Mara); Center for Research, Education and Quality. Pediatrix Medical Group, Sunrise Florida (Clark).

Corresponding Author: Kevin R. Ellsworth, MD, Division of Neonatal Medicine, Mayo Clinic, 200 First St SW, Rochester, MN 55905 (kevinbni@gmail.com). 
ulmonary hypoplasia $(\mathrm{PH})$ is a relatively rare diagnosis that is associated with high rates of mortality and morbidity, especially in preterm neonates. ${ }^{1-7}$ Most cases occur in association with complications of pregnancy that disrupt lung development, such as oligohydramnios or rupture of membranes at periviable gestational ages. ${ }^{8,9}$ Because blood vessel growth in the lung parallels airway development, $\mathrm{PH}$ is often complicated by persistent pulmonary hypertension of the newborn (PPHN). Pulmonary hypertension is a major contributor to physiologic compromise in these patients, including severe, refractory hypoxemic respiratory failure. To date, to our knowledge, no postnatal therapy has been shown to consistently increase survival in preterm neonates with $\mathrm{PH}$.

Inhaled nitric oxide (iNO) is an approved treatment for neonates older than 34 weeks' gestational age who have hypoxemic respiratory failure associated with PPHN. The drug has been tested in preterm neonates, ${ }^{10-27}$ but in aggregate, these trials demonstrate that iNO neither reduces mortality nor prevents major morbidities. As a selective pulmonary vasodilator, iNO would be expected to benefit patients whose hypoxemic respiratory failure is predominantly characterized by vascular pathophysiology, as is the case with $\mathrm{PH}$. Small subgroup analyses of preterm trial data and several case series suggest that preterm neonates with $\mathrm{PH}$ may derive a survival benefit from iNO. ${ }^{28-38}$ Unfortunately, the infrequency of PH limits our ability to derive meaningful conclusions from these studies and, some would argue, precludes the future conduct of randomized clinical trials. ${ }^{39-41}$

Some have called for alternative study designs to address the knowledge gap. ${ }^{39,41,42}$ In response to this unmet need, we performed a propensity score-matched cohort study using a large data set to test our hypothesis that early iNO exposure improves survival in preterm neonates with $\mathrm{PH}$.

\section{Methods}

\section{Study Design and Data Source}

We performed this cohort study using a deidentified data set approved by the Western institutional review board and considered exempt by the Mayo Clinic institutional review board. The data set was extracted from the Pediatrix Medical Group Clinical Data Warehouse. ${ }^{43-50}$ The Clinical Data Warehouse stores clinical information documented by Pediatrix Medical Group clinicians in more than 350 neonatal intensive care units in 35 US states and Puerto Rico. Data generated from daily medical documentation (eg, admission, progress, and discharge notes) and billing worksheets are consolidated within the warehouse at the end of each neonate's neonatal intensive care unit stay, deidentified, and made compliant with the Health Insurance Portability and Accountability Act of 1996. Data can then be configured into tables that can be joined and queried for quality improvement and research. ${ }^{43,51,52}$

\section{Study Population}

We identified all neonates who were admitted to a Pediatrix Medical Group neonatal intensive care unit and were discharged during the calendar years 2000 through 2014. Our

\section{Key Points}

Question Does early treatment with inhaled nitric oxide improve survival in extremely preterm neonates diagnosed with pulmonary hypoplasia?

Findings This cohort study compared outcomes within a propensity score-matched cohort of neonates born at less than 29 weeks' gestation with respiratory failure and a clinical diagnosis of pulmonary hypoplasia who were or were not treated with inhaled nitric oxide. Treatment during the first week of life was not significantly associated with improved in-hospital survival, even among neonates with a concomitant diagnosis of pulmonary hypertension.

Meaning There may not be a benefit to prescribing inhaled nitric oxide to extremely preterm neonates with pulmonary hypoplasia, whether or not pulmonary hypertension is also suspected.

initial sample included those who were born at 22 weeks 0 days' to 28 weeks and 6 days' gestation with a birth weight of $400 \mathrm{~g}$ or more who were diagnosed with at least 1 form of respiratory distress. We identified those who received the specific diagnosis of $\mathrm{PH}$ and excluded neonates with other forms of parenchymal lung disease (eg, pneumonia). We also excluded nonsingletons; those diagnosed with aneuploidy, congenital diaphragmatic hernia, congenital heart disease, hydrops, or other major congenital anomalies; and neonates who died in the delivery room or were not admitted for neonatal intensive care (eg, comfort care measures only).

The resulting unmatched cohort was composed of neonates diagnosed with $\mathrm{PH}$, some of whom also received a concomitant diagnosis of PPHN. There were no predetermined criteria for either the PH or PPHN diagnoses-in other words, the presence or absence of these conditions was entirely at the discretion of the treating neonatologist. For each neonate, we obtained various maternal and baseline neonatal characteristics, including birth size assessment based on intrauterine growth curves. ${ }^{49}$ The Clinical Data Warehouse does not contain information on specific iNO dosages, oxygenation indices, or echocardiographic findings.

\section{Outcomes}

The primary outcome was in-hospital mortality, which was defined as death prior to transfer or discharge home. Secondary outcomes were any-stage necrotizing enterocolitis (NEC); retinopathy of prematurity requiring treatment (tROP); chronic lung disease (CLD; defined as supplemental oxygen use and/or positive pressure requirement at 36 weeks' postmenstrual age); and periventricular leukomalacia (PVL).

\section{Statistical Analyses}

Statistical analyses were performed using SAS, version 9.4 (SAS Institute, Inc). Because iNO exposure was not randomly assigned in this retrospective cohort, we used propensity score (PS) matching to reduce the imbalance of measured baseline characteristics between patients who received iNO during the first 7 days of life and their matched referents. ${ }^{53,54}$ Since iNO could have been initiated at any time during the first 7 days of 


\begin{tabular}{|c|c|c|c|c|c|c|}
\hline \multirow[b]{2}{*}{ Characteristic } & \multicolumn{3}{|c|}{ Full Cohort, No. (\%) } & \multicolumn{3}{|c|}{ Matched Cohort, No. (\%) } \\
\hline & $\begin{array}{l}\text { iNO Within } \\
\text { First } 7 \mathrm{~d} \\
(\mathrm{n}=185)\end{array}$ & $\begin{array}{l}\text { No iNO Within } \\
\text { First 7 d } \\
(n=582)\end{array}$ & $\begin{array}{l}\text { Standardized } \\
\text { Difference } \\
\text { (Absolute Value) }\end{array}$ & $\begin{array}{l}\text { Exposed } \\
(n=151)\end{array}$ & $\begin{array}{l}\text { Referent } \\
(n=151)\end{array}$ & $\begin{array}{l}\text { Standardized } \\
\text { Difference } \\
\text { (Absolute Value) }\end{array}$ \\
\hline \multicolumn{7}{|l|}{ Maternal Characteristics } \\
\hline Prolonged rupture of membrane & $89(48.1)$ & $335(57.6)$ & 0.19 & $77(51.0)$ & $77(51.0)$ & 0 \\
\hline Oligohydramnios & $13(7.0)$ & $87(14.9)$ & 0.26 & $13(8.6)$ & $15(9.9)$ & 0.05 \\
\hline Antenatal steroids given & $163(88.1)$ & $462(79.4)$ & 0.24 & $131(86.8)$ & $133(88.1)$ & 0.04 \\
\hline \multicolumn{7}{|l|}{ Infant Characteristics } \\
\hline \multicolumn{7}{|l|}{ Respiratory diagnosis group } \\
\hline Pulmonary hypoplasia without PPHN & $46(24.9)$ & $478(82.1)$ & \multirow{2}{*}{1.40} & $46(30.5)$ & $46(30.5)$ & \multirow{2}{*}{0} \\
\hline Pulmonary hypoplasia with PPHN & $139(75.1)$ & $104(17.9)$ & & $105(69.5)$ & $105(69.5)$ & \\
\hline Gestational age, mean (SD), wk & $26.8(1.7)$ & $26.1(1.8)$ & 0.42 & $26.7(1.7)$ & $26.7(1.6)$ & 0 \\
\hline Birth weight, mean (SD), kg & $1.04(0.29)$ & $0.90(0.28)$ & 0.49 & $1.02(0.30)$ & $1.03(0.27)$ & 0.03 \\
\hline \multicolumn{7}{|l|}{ Birth size assessment } \\
\hline Small for gestational age & $10(5.4)$ & $62(10.7)$ & 0.19 & $10(6.6)$ & $7(4.6)$ & 0.09 \\
\hline Appropriate for gestational age & $141(76.2)$ & $444(76.3)$ & 0.002 & $113(74.8)$ & $112(74.2)$ & 0.02 \\
\hline Large for gestational age & $34(18.4)$ & $76(13.1)$ & 0.15 & $28(18.5)$ & $32(21.2)$ & 0.07 \\
\hline \multicolumn{7}{|l|}{ Sex } \\
\hline Male & $108(58.4)$ & $341(58.6)$ & \multirow{2}{*}{0.004} & $87(57.6)$ & $89(58.9)$ & \multirow{2}{*}{0.03} \\
\hline Female & $77(41.6)$ & $241(41.4)$ & & $64(42.4)$ & $62(41.1)$ & \\
\hline \multicolumn{7}{|l|}{ Race/ethnicity } \\
\hline White & $97(52.4)$ & $311(53.4)$ & 0.02 & $79(52.3)$ & $78(51.7)$ & 0.01 \\
\hline Asian & $1(0.5)$ & $16(2.7)$ & 0.17 & $1(0.7)$ & $1(0.7)$ & 0 \\
\hline Black & $41(22.2)$ & $131(22.5)$ & 0.01 & $32(21.2)$ & $37(24.5)$ & 0.08 \\
\hline Hispanic & $30(16.2)$ & $93(16.0)$ & 0.01 & $25(16.6)$ & $26(17.2)$ & 0.02 \\
\hline Other & $16(8.6)$ & $31(5.3)$ & 0.13 & $14(9.3)$ & $9(6.0)$ & 0.13 \\
\hline \multicolumn{7}{|l|}{ Calendar year $^{\mathrm{a}}$} \\
\hline $2000-2004$ & $18(9.7)$ & $193(33.2)$ & \multirow{3}{*}{0.71} & 18 (11.9) & 27 (17.9) & \multirow{3}{*}{0.14} \\
\hline $2005-2009$ & $62(33.5)$ & $202(34.7)$ & & $51(33.8)$ & $51(33.8)$ & \\
\hline $2010-2014$ & $105(56.8)$ & $187(32.1)$ & & $82(54.3)$ & $73(48.3)$ & \\
\hline \multicolumn{7}{|l|}{ Inborn/outborn status } \\
\hline Inborn & $160(86.5)$ & $548(94.2)$ & \multirow{2}{*}{0.26} & $131(86.8)$ & $135(89.4)$ & \multirow{2}{*}{0.08} \\
\hline Outborn & $25(13.5)$ & $34(5.8)$ & & $20(13.2)$ & $16(10.6)$ & \\
\hline Surfactant given & $172(93.0)$ & $472(81.1)$ & 0.36 & $139(92.1)$ & $137(90.7)$ & 0.05 \\
\hline \multicolumn{7}{|l|}{ Maximal respiratory support over days $0-2$} \\
\hline Room air & 0 & $7(1.2)$ & \multirow{4}{*}{0.45} & 0 & 0 & \multirow{4}{*}{0.03} \\
\hline Nasal CPAP & 0 & $6(1.0)$ & & 0 & 0 & \\
\hline Conventional mechanical ventilation & $10(5.4)$ & $117(20.1)$ & & $9(6.0)$ & $10(6.6)$ & \\
\hline High-frequency oscillatory ventilation & $175(94.6)$ & $452(77.7)$ & & $142(94.0)$ & $141(93.4)$ & \\
\hline At least 1 vasopressor reported on days $0-3$ & $154(83.2)$ & $309(53.1)$ & 0.68 & $122(80.8)$ & $122(80.8)$ & 0 \\
\hline
\end{tabular}

Abbreviations: CPAP, continuous positive airway pressure; iNO, inhaled nitric oxide; PPHN, persistent pulmonary hypertension of the newborn.

a This is categorized for presentation purposes.

life, we used a sequential iterative risk set approach to match a patient who initiated iNO on day $t$ (exposed) with another patient (referent) with similar baseline characteristics who had not received iNO as of day $t$, separately, for $t=0$ to $7 .{ }^{55,56}$ First, we created a risk set of all patients at risk for receiving iNO on day $t$. Using all the patients in this risk set, we fit a multivariable logistic model to estimate PS values (defined as the probability that a patient would receive iNO on day $t$, conditional on the measured baseline covariates). This model included main effect terms for each of the variables listed in Table 1; gestational age, birth weight, and calendar year were mod- eled as linear terms, with an interaction between gestational age and birth weight. For each patient who received iNO on day $t, 1$ patient was randomly selected without replacement from the pool of patients who did not receive iNO on day $t$ and matched on the respiratory diagnosis ( $\mathrm{PH}$ without $\mathrm{PPHN}$ or $\mathrm{PH}$ with PPHN) and within 0.2 SDs of the logit of the PS values. We repeated this matching process sequentially for each of days $t 0$ through 7 , only excluding patients from each risk set who had died, been transferred or discharged, or received iNO prior to time $t$. We combined all matched pairs (exposed and their matched referents) into a single PS-matched cohort for analysis. 


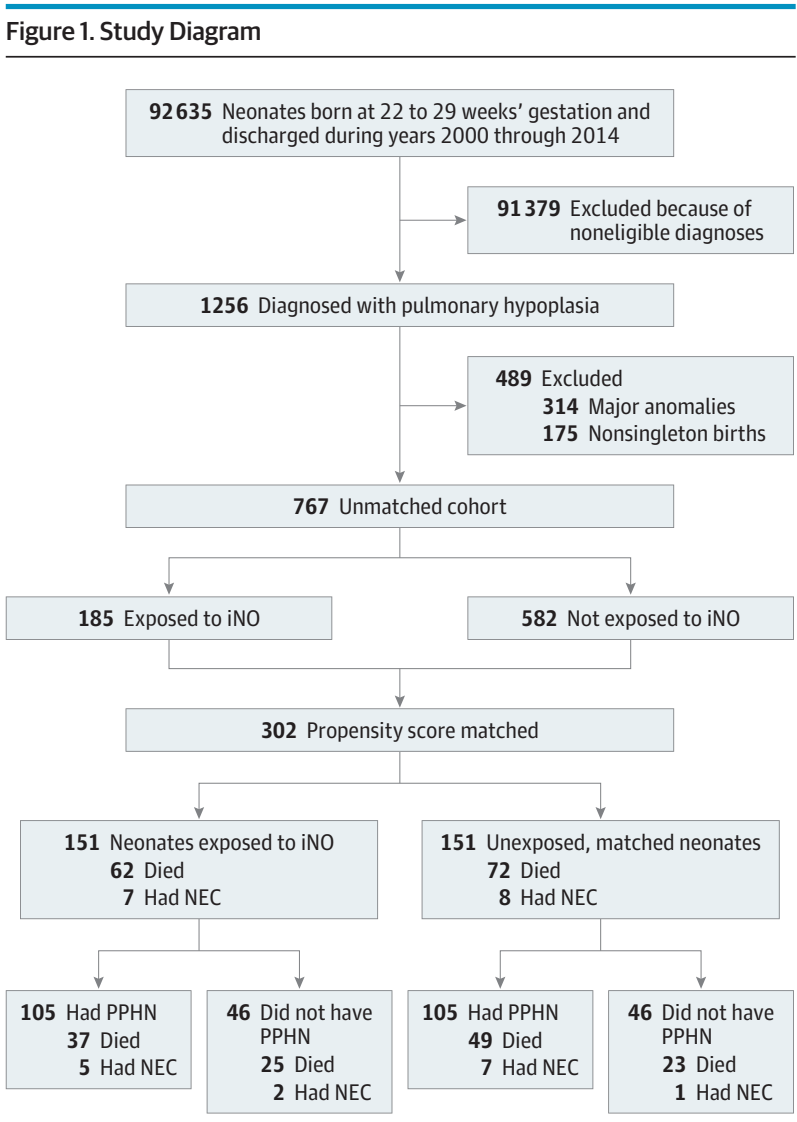

iNO indicates inhaled nitric oxide; NEC, necrotizing enterocolitis; PPHN, persistent pulmonary hypertension of the newborn.

The date of iNO initiation for the iNO exposed was defined as the index date for both the iNO-exposed patients and their matched referents.

We evaluated covariate imbalance between theiNO-exposed group and unexposed group by determining the standardized difference for each baseline covariate. We defined the standardized difference for a continuous covariate as the absolute difference in group means divided by an estimate of the pooled standard deviation. The derivation was similar for nominal covariates. We considered a standardized difference less than 0.10 as negligible covariate imbalance between groups. ${ }^{57}$

To assess the association between iNO status and inhospital mortality using the PS-matched cohort, we used a Cox proportional hazards model using age as the time scale. ${ }^{58}$ The counting process formulation of a Cox model was used to handle the delayed entry of the patients into the risk sets since patients entered a risk set at their respective age at the index date (instead of birth) and exited at the age of their death, transfer, or discharge. To account for patients included in both groups in the matched cohort, we used robust sandwich covariance estimates in the Cox models. We summarized associations using the HR and corresponding 95\% CI.

We used the same time-to-event analysis methods to compare NEC between the matched treatment groups. For the 3 remaining secondary outcomes, we identified separate PS-matched subcohorts of patients who were eligible for evalu- ation of these diagnoses: for tROP, patients evaluated for ROP; for CLD, patients hospitalized at 36 weeks' corrected gestational age; for PVL, patients with brain imaging. Because iNO treatment status was known at the time these secondary outcomes were assessed, we performed matching in a single step for each subcohort. We then evaluated the association between iNO and each secondary outcome using logistic regression, handling iNO status as a standard baseline covariate. Associations were summarized using odds ratios (ORs) and corresponding 95\% CIs.

A sensitivity analysis was performed for the mortality and NEC outcomes to alternatively handle those matched referents who subsequently received iNO within the first 7 days of life. Among the 151 referents in the PS-matched cohort, 35 received iNO within the first 7 days of life, of whom only 12 were also included in the matched cohort as exposed because there were no matched referents for the remaining 23 based on our matching calipers. In the sensitivity analysis using all 151 PS-matched pairs, we censored the follow-up of these 35 referents at the age they received iNO rather than at the age of their death, transfer, or discharge. In this manner, the 12 matched referents who were also in the exposed group were handled as unexposed in the time interval prior to receiving iNO and as exposed in the time interval after receiving iNO. These primary and sensitivity analysis methods were also used to assess outcomes in subgroups defined based on diagnosis status (PH with PPHN and PH without PPHN).

\section{Results}

Of the 92635 neonates meeting gestational age, birth weight, and calendar year criteria, 1256 (1.4\%) were diagnosed with PH as a cause of their respiratory distress (Figure 1). After exclusion of neonates with congenital anomalies and those from nonsingleton pregnancies, 767 remained as the unmatched analysis cohort. Of these neonates, 185 of 767 (24.1\%) had iNO initiated within the first 7 days after birth, with most exposed on the first day of life $(\mathrm{n}=123$ [66.5\%] on day $0 ; \mathrm{n}=54$ [29.2\%] on day $1 ; n=5[2.7 \%]$ on day 2 ; and $n=3[1.6 \%]$ on days 3 through 7). Baseline characteristics of neonates in the full (unmatched) cohort are shown in Table 1. Compared with neonates untreated with iNO, those who did receive iNO were more often diagnosed with both $\mathrm{PH}$ and PPHN, received highfrequency oscillatory ventilation more frequently, and were more likely to be prescribed at least 1 vasopressor during the first 3 days of life. The use of iNO in patients with $\mathrm{PH}$ increased from 18 of 211 (8.5\%) in 2000 through 2004 to 105 of 292 (36.0\%) in the period of 2010 through 2014; this meant that most neonates exposed were discharged within these last 5 years $(n=105 ; 56.8 \%)$.

All of the variables listed in Table 1 were included in the model to derive the PS values. The PS-matched cohort consisted of 151 pairs of exposed and unexposed neonates. Compared with the full unmatched cohort, the measured covariates in the matched cohort were more balanced, with most standardized differences falling below the recommended threshold of 0.10 (eFigure 1 in the Supplement) and a slight residual imbalance for 
Figure 2. Overall Survival by iNO Exposure Status of Patients in the Matched Cohort

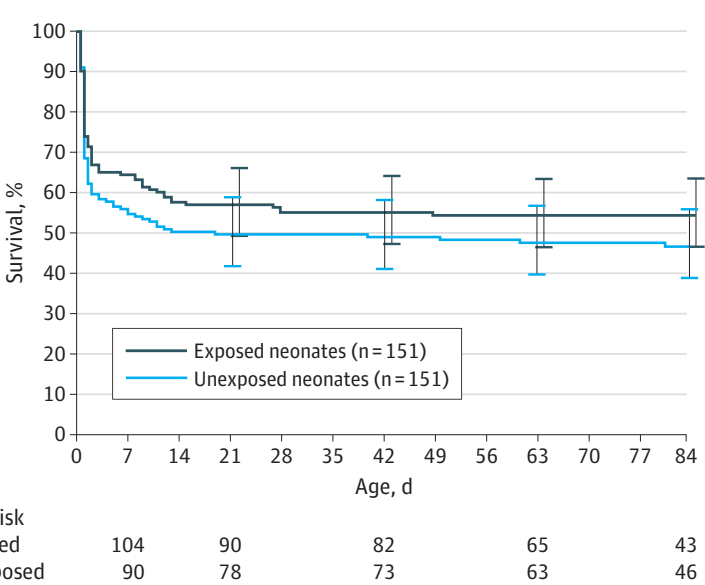

$\begin{array}{lrrrrr}\text { No. at risk } & & & 65 & 43 \\ \text { Exposed } & 104 & 90 & 82 & 63 & 46 \\ \text { Unexposed } & 90 & 78 & 73 & 63\end{array}$

The survival estimates were derived from a Cox model with patients entering the risk set with their respective age as the index date. iNO indicates inhaled nitric oxide; NEC, necrotizing enterocolitis; $\mathrm{PH}$, pulmonary hypoplasia; PPHN, persistent pulmonary hypertension of the newborn.

calendar year and the racial/ethnic category other. Half of the neonates in the matched cohort were born following prolonged rupture of membranes, and nearly $90 \%$ were exposed to antenatal steroids (Table 1). All matched pairs were mechanically ventilated during the first 2 days of life, including more than $90 \%$ in each group receiving high-frequency oscillatory ventilation. Approximately $80 \%$ of these neonates required at least 1 vasopressor during the first 3 days of life.

Among the 151 neonates in the iNO group, 62 died inhospital at a median age of 1 day (interquartile range [IQR], 1-9 days) and the remaining 89 were discharged or transferred at a median age of 81 days (IQR, 59-103 days). Among the 151 matched referents, 72 died in-hospital at a median age of 1 day (IQR, 1-5 days), and the remaining 79 were discharged or transferred at a median age of 86 days (IQR, 62-104 days). Contrary to our hypothesis, we did not observe a statistically significant association between iNO treatment and mortality among these patients (HR, 0.79; 95\% CI, 0.57-1.11, adjusted for calendar year to address the residual imbalance in the propensity matching; Figure 2).

Necrotizing enterocolitis was diagnosed in 7 exposed neonates at a median of 26 days of life (IQR, 14-32 days) and in 8 referents at a median of 14 days of life (IQR, 10-21 days). There was no statistically significant association between iNO exposure and NEC (HR, 0.73; 95\% CI, 0.27-2.01, adjusted for calendar year; eFigure 2 in the Supplement). Additionally, early treatment with iNO was not associated with differences in any of the other secondary outcomes (Table 2).

When the matched cohort was further stratified by the presence or absence of a concomitant diagnosis of PPHN, the covariates were slightly more unbalanced, in part because of small sample sizes (eTable 1 in the Supplement). Among neonates diagnosed with both $\mathrm{PH}$ and PPHN, those who received iNO had a 33\% reduced risk of in-hospital mortality compared with matched referents; however, this difference was not signifi-
Table 2. Comparison of Secondary Outcomes With Matched Pairs of Exposed and Referent Neonates

\begin{tabular}{|c|c|c|c|}
\hline \multirow[b]{2}{*}{ Clinical Characteristic } & \multicolumn{2}{|l|}{ No. (\%) } & \multirow{2}{*}{$\begin{array}{l}\text { Odds Ratio } \\
(95 \% \mathrm{Cl})\end{array}$} \\
\hline & Exposed & Unexposed & \\
\hline \multicolumn{4}{|l|}{ ROP treated } \\
\hline $\begin{array}{l}\text { No. of neonates with } \\
\text { ROP evaluated }\end{array}$ & 108 & 191 & NA \\
\hline $\begin{array}{l}\text { No. of matched pairs } \\
\text { used with ROP } \\
\text { evaluated }\end{array}$ & 44 & 44 & NA \\
\hline No & $44(100)$ & $44(100)$ & NA \\
\hline Yes & $0(0)$ & $0(0)$ & $N A^{a}$ \\
\hline \multicolumn{4}{|l|}{ Chronic lung disease } \\
\hline $\begin{array}{l}\text { No. of neonates still in } \\
\text { hospital at } C G A \geq 36 \text { wk }\end{array}$ & 91 & 162 & NA \\
\hline $\begin{array}{l}\text { No. of matched pairs } \\
\text { used that were still in } \\
\text { hospital at } C G A \geq 36 \text { wk }\end{array}$ & 38 & 38 & NA \\
\hline No & $11(29)$ & $9(24)$ & NA \\
\hline Yes & $27(71)$ & $29(76)$ & $0.78(0.28-2.19)^{\mathrm{b}}$ \\
\hline \multicolumn{4}{|l|}{$\begin{array}{l}\text { Periventricular } \\
\text { leukomalacia }\end{array}$} \\
\hline $\begin{array}{l}\text { No. of neonates with } \\
\text { cranial imaging }\end{array}$ & 149 & 293 & NA \\
\hline $\begin{array}{l}\text { No. of matched pairs } \\
\text { used with cranial } \\
\text { imaging }\end{array}$ & 80 & 80 & NA \\
\hline No & $75(94)$ & $76(95)$ & NA \\
\hline Yes & $5(6)$ & $4(5)$ & $1.27(0.33-4.90)$ \\
\hline
\end{tabular}

Abbreviations: CGA, corrected gestational age; iNO, inhaled nitric oxide; NA, not applicable; PS, propensity score; ROP, retinopathy of prematurity.

a The odds ratio was not estimated because of the lack of events in both groups. ${ }^{\mathrm{b}}$ Adjusted for inborn/outborn status.

cant (HR, 0.67; 95\% CI, 0.45-1.01; Figure 3). Patients whose PH was not accompanied by a concomitant diagnosis of PPHN experienced similar mortality irrespective of iNO treatment status (HR, 1.11; 95\% CI, 0.61-2.02; Figure 3). Last, among the $\mathrm{PH}$ with PPHN and PH without PPHN subgroups, we were unable to detect statistically significant associations between iNO treatment and NEC (PH with PPHN: HR, 0.55; 95\% CI, 0.18-1.73; PH without PPHN: HR, 2.16; 95\% CI, 0.19-24.1) or any other secondary outcome (eTable 2 in the Supplement).

The results from the sensitivity analysis were consistent with the main analysis. In the sensitivity analysis, we found that there was no significant difference in the risk of inhospital mortality between exposed neonates and their matched referents (HR, 0.86; 95\% CI, 0.60-1.23, adjusted for calendar year; eFigure 3 in the Supplement) or in the risk of NEC between the 2 groups (HR, 0.63; 95\% CI, 0.21-1.92, adjusted for calendar year; eFigure 4 in the Supplement). Likewise, in subgroup sensitivity analysis, the HRs for in-hospital mortality were consistent with the main analysis (PH with PPHN: HR, 0.72; 95\% CI, 0.45-1.15; PH without PPHN: HR, 1.09; 95\% CI, 0.62-1.92; eFigure 5 in the Supplement).

\section{Discussion}

We determined that iNO treatment during the first week of life was not associated with improved survival in this cohort, which 
Figure 3. Overall Survival by Inhaled Nitric Oxide Exposure Status of Patients in the Matched Cohort Diagnosed With Pulmonary Hypoplasia With and Without Persistent Pulmonary Hypertension of The Newborn

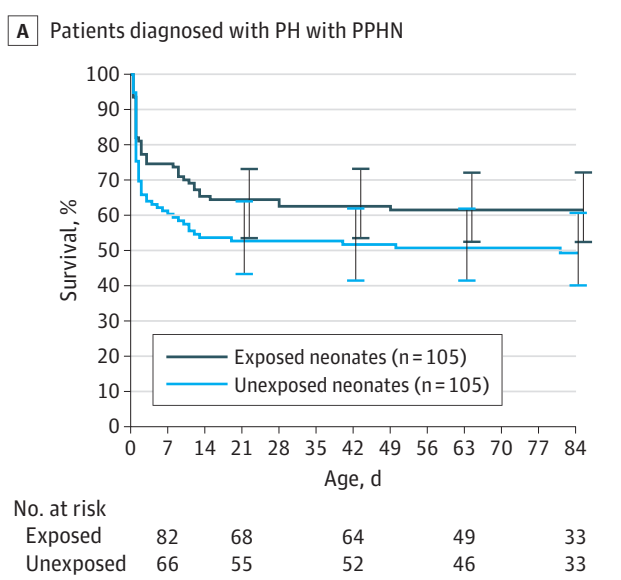

B Patients diagnosed with $\mathrm{PH}$ without PPHN

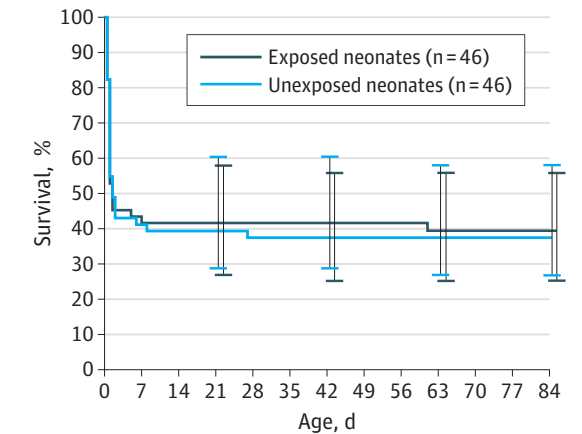

$\begin{array}{llllll}\text { No. at risk } & & & & & \\ \text { Exposed } & 22 & 22 & 18 & 16 & 10 \\ \text { Unexposed } & 24 & 23 & 21 & 17 & 13\end{array}$

The survival estimates were derived from a Cox model with patients entering the risk set at their respective age at the index date. is to our knowledge the largest reported cohort of extremely preterm neonates with PH. Similarly, iNO treatment was not associated with reductions in tROP, CLD, or PVL among those who survived to be evaluated for these comorbidities. Among our initial sample of more than 90000 patients, we observed a prevalence of PH similar to levels reported previously. ${ }^{1-3,5-7}$ Additionally, the patient characteristics and clinical outcomes of our matched cohort are similar to those of prior studies. ${ }^{1,2,10,28-38}$

We hypothesized that early iNO treatment would be associated with lower mortality among preterm neonates diagnosed with PH. Previous studies suggested that preterm neonates with $\mathrm{PH}$ secondary to prolonged rupture of membranes may represent a subpopulation for whom iNO might confer a survival advantage. ${ }^{29-32,34,36-38,59-61}$ This is especially compelling given that these neonates may be affected by a transient defect in nitric oxide generation. ${ }^{28}$ In fact, the possibility that preterm neonates with prolonged rupture of membranesinduced PH might benefit from iNO has been acknowledged by some organizations that otherwise discourage the routine or rescue use of iNO in preterm neonates. ${ }^{41,62,63}$

Yet we did not disprove the null hypothesis in this study. One explanation could be that our matched cohort contains patients who were affected by a broad spectrum of disease, because $\mathrm{PH}$ may range from negligible to severe. ${ }^{64}$ The unequivocal diagnosis of $\mathrm{PH}$ requires lung biopsy or autopsy, and so, for the practicing neonatologist, $\mathrm{PH}$ is essentially a diagnosis of exclusion. ${ }^{34}$ This lack of certainty or diagnostic precision could have influenced the manner in which clinicians documented the presence of $\mathrm{PH}$, although this would have affected both exposed and referent groups.

The targeted use of iNO in preterm neonates with $\mathrm{PH}$ and PPHN is supported by some organizations, including the American Heart Association, the American Thoracic Society, and the Pediatric Pulmonary Hypertension Network. ${ }^{41,65,66}$ This seems rational, given that $\mathrm{PH}$-related $\mathrm{PPHN}$ has characteristics that may render it more acutely responsive to iNO than PPHN that results from parenchymal lung disease. ${ }^{59,65,67,68}$ However, an acute clinical response to iNO may not translate into a survival benefit. ${ }^{69}$

While we did not identify a beneficial association between iNO exposure and survival among extremely preterm neonates with $\mathrm{PH}$, there is sufficient uncertainty in our subgroup analysis of those with PPHN that a prospective randomized clinical trial is warranted. Others have argued that such a trial would be impractical, given the relative rarity of the disease, ${ }^{39-41,68}$ the associated high mortality rates, and complicating comorbid conditions, ${ }^{33,67}$ as well as the lack of equipoise regarding the safety and efficacy of iNO. ${ }^{40,41,68}$ In our sample of more than 90000 neonates born before 29 weeks' gestation, $1.4 \%$ were diagnosed with $\mathrm{PH}$, of whom $75 \%$ had no major anomalies. Considering these results, and that nearly 30000 neonates are born before 28 weeks' gestation in the United States each year, ${ }^{70}$ perhaps 300 patients could qualify annually for a randomized study. Based on the in-hospital mortality rates ( $41 \%$ and $48 \%$ ) and HR (0.79) observed in this PS-matched cohort, approximately 600 neonates in each group (iNO exposed and unexposed) would be required to detect such a difference in a randomized study with $80 \%$ power ( $a=.05,2$-sided).

\section{Limitations}

We did not observe improved survival among neonates whose $\mathrm{PH}$ was accompanied by a concomitant diagnosis of PPHN, although the benefit of iNO therapy may have been underestimated because of the small size of our study population and/or other confounding factors. In addition, ascertainment bias could have influenced the classification of patients between the 2 subgroups. We were surprised to find that the mortality of referents in the PH with PPHN cohort was not significantly worse than that of referents in the PH without PPHN cohort (HR, 0.74; 95\% CI, 0.44-1.27), because the concomitant diagnosis of PPHN is associated with higher mortality among extremely preterm neonates with respiratory distress syndrome. ${ }^{69}$ This finding raises the possibility that some patients in the $\mathrm{PH}$ without PPHN cohort were affected by PPHN that either was clinically 
undetected or was simply undocumented. There is evidence of the second explanation: patients in the $\mathrm{PH}$ with PPHN subgroup were more likely to have documented echocardiographic examinations than were those in the $\mathrm{PH}$ without PPHN cohort (50.0\% vs $29.3 \%$, respectively). While we cannot be sure, a lower rate of cardiac imaging could have prevented Pediatrix Medical Group clinicians from identifying comorbid PPHN among these patients.

\section{Conclusions}

Early treatment with iNO is not associated with improved survival in preterm neonates diagnosed with $\mathrm{PH}$, including those with a concomitant diagnosis of PPHN. A randomized clinical trial of iNO in this population of infants with $\mathrm{PH}$ and concomitant PPHN is needed, despite the perceived barriers thereto.

\section{ARTICLE INFORMATION}

\section{Accepted for Publication: March 4, 2018.}

Published Online: May 7, 2018.

doi:10.1001/jamapediatrics.2018.0761

Author Contributions: Ms Weaver had full access to all of the data in the study and takes responsibility for the integrity of the data and the accuracy of the data analysis.

Study concept and design: K. Ellsworth,

M. Ellsworth, Weaver, Clark, Carey.

Acquisition, analysis, or interpretation of data: All authors.

Drafting of the manuscript: K. Ellsworth,

M. Ellsworth, Weaver, Clark, Carey.

Critical revision of the manuscript for important

intellectual content: All authors.

Statistical analysis: Weaver, Mara.

Administrative, technical, or material support: Clark,

Carey.

Study supervision: Carey.

Conflict of Interest Disclosures: Dr Clark reports grant support and support for CME presentations from Mallinckrodt Pharmaceuticals. No other disclosures were reported.

Funding/Support: This study was supported by the Mayo Clinic Children's Research Center and the National Center for Advancing Translational Sciences (grant UL1 TR002377).

Disclaimer: The contents of this article are solely the responsibility of the authors and do not necessarily represent the official views of the $\mathrm{NIH}$.

Additional Contributions: We thank Christopher Colby, MD, and Garth Asay, MD, Division of Neonatal Medicine, Mayo Clinic, and Lindsey Sangaralingham, MPH, Mayo Clinic Center for the Science of Health Care Delivery, for their help initiating this study. They were not compensated for their contributions to this study.

\section{REFERENCES}

1. Rubaltelli FF, Bonafe L, Tangucci M, Spagnolo A, Dani C; Italian Group of Neonatal Pneumology. Epidemiology of neonatal acute respiratory disorders. A multicenter study on incidence and fatality rates of neonatal acute respiratory disorders according to gestational age, maternal age, pregnancy complications and type of delivery. Biol Neonate. 1998;74(1):7-15.

2. Knox WF, Barson AJ. Pulmonary hypoplasia in a regional perinatal unit. Early Hum Dev. 1986;14(1): 33-42.

3. Moessinger AC, Santiago A, Paneth NS, Rey HR, Blanc WA, Driscoll JM Jr. Time-trends in necropsy prevalence and birth prevalence of lung hypoplasia. Paediatr Perinat Epidemiol. 1989;3(4):421-431.

4. Laudy JA, Wladimiroff JW. The fetal lung. 2: pulmonary hypoplasia. Ultrasound Obstet Gynecol. 2000;16(5):482-494.
5. Husain AN, Hessel RG. Neonatal pulmonary hypoplasia: an autopsy study of 25 cases. Pediatr Pathol. 1993;13(4):475-484.

6. Page DV, Stocker JT. Anomalies associated with pulmonary hypoplasia. Am Rev Respir Dis. 1982;125 (2):216-221.

7. Wigglesworth JS, Desai R. Is fetal respiratory function a major determinant of perinatal survival? Lancet. 1982;1(8266):264-267.

8. Porter HJ. Pulmonary hypoplasia. Arch Dis Child Fetal Neonatal Ed. 1999;81(2):F81-F83.

9. Nakamura Y, Harada K, Yamamoto I, et al. Human pulmonary hypoplasia. statistical, morphological, morphometric, and biochemical study. Arch Pathol Lab Med. 1992;116(6):635-642.

10. Subhedar NV, Shaw NJ. Changes in oxygenation and pulmonary haemodynamics in preterm infants treated with inhaled nitric oxide. Arch Dis Child Fetal Neonatal Ed. 1997;77(3):F191-F197.

11. Kinsella JP, Walsh WF, Bose CL, et al. Inhaled nitric oxide in premature neonates with severe hypoxaemic respiratory failure: a randomised controlled trial. Lancet. 1999;354(9184):1061-1065.

12. Srisuparp P, Heitschmidt M, Schreiber MD. Inhaled nitric oxide therapy in premature infants with mild to moderate respiratory distress syndrome. J Med Assoc Thai. 2002;85(suppl 2): S469-S478.

13. Schreiber MD, Gin-Mestan K, Marks JD, Huo D, Lee G, Srisuparp P. Inhaled nitric oxide in premature infants with the respiratory distress syndrome. N Engl J Med. 2003;349(22):2099-2107.

14. Field D, Elbourne D, Truesdale A, et al; INNOVO Trial Collaborating Group. Neonatal ventilation with inhaled nitric oxide versus ventilatory support without inhaled nitric oxide for preterm infants with severe respiratory failure: the INNOVO multicentre randomised controlled trial (ISRCTN 17821339). Pediatrics. 2005;115(4):926-936.

15. Van Meurs KP, Wright LL, Ehrenkranz RA, et al; Preemie Inhaled Nitric Oxide Study. Inhaled nitric oxide for premature infants with severe respiratory failure. N Engl J Med. 2005;353(1):13-22.

16. Van Meurs KP, Hintz SR, Ehrenkranz RA, et al Inhaled nitric oxide in infants $>1500 \mathrm{~g}$ and $<34$ weeks gestation with severe respiratory failure. J Perinatol. 2007;27(6):347-352.

17. Hascoet JM, Fresson J, Claris O, et al. The safety and efficacy of nitric oxide therapy in premature infants. J Pediatr. 2005;146(3):318-323.

18. Dani C, Bertini G, Pezzati M, Filippi L, Cecchi A, Rubaltelli FF. Inhaled nitric oxide in very preterm infants with severe respiratory distress syndrome. Acta Paediatr. 2006;95(9):1116-1123.

19. Kinsella JP, Cutter GR, Walsh WF, et al. Early inhaled nitric oxide therapy in premature newborns with respiratory failure. N Engl J Med. 2006;355(4): 354-364.

20. Ballard RA, Truog WE, Cnaan A, et al; NO CLD Study Group. Inhaled nitric oxide in preterm infants undergoing mechanical ventilation. $N$ Engl J Med. 2006;355(4):343-353.

21. Mercier JC, Hummler $H$, Durrmeyer $X$, et al; EUNO Study Group. Inhaled nitric oxide for prevention of bronchopulmonary dysplasia in premature babies (EUNO): a randomised controlled trial. Lancet. 2010;376(9738):346-354.

22. The Franco-Belgium Collaborative NO Trial Group. Early compared with delayed inhaled nitric oxide in moderately hypoxaemic neonates with respiratory failure: a randomised controlled trial. Lancet. 1999;354(9184):1066-1071.

23. Barrington $\mathrm{KJ}$, Finer N. Inhaled nitric oxide for respiratory failure in preterm infants. Cochrane Database Syst Rev. 2010;(12):CD000509.

24. Donohue PK, Gilmore MM, Cristofalo E, et al. Inhaled nitric oxide in preterm infants: a systematic review. Pediatrics. 2011;127(2):e414-e422.

25. Barrington KJ, Finer N, Pennaforte T. Inhaled nitric oxide for respiratory failure in preterm infants. Cochrane Database Syst Rev. 2017;1:CD000509.

26. Askie LM, Ballard RA, Cutter GR, et al; Meta-analysis of Preterm Patients on Inhaled Nitric Oxide Collaboration. Inhaled nitric oxide in preterm infants: an individual-patient data meta-analysis of randomized trials. Pediatrics. 2011;128(4):729-739.

27. Hasan SU, Potenziano J, Konduri GG, et al; Newborns Treated With Nitric Oxide (NEWNO) Trial Group. Effect of inhaled nitric oxide on survival without bronchopulmonary dysplasia in preterm infants: a randomized clinical trial. JAMA Pediatr. 2017;171(11):1081-1089.

28. Aikio O, Metsola J, Vuolteenaho R, Perhomaa M, Hallman M. Transient defect in nitric oxide generation after rupture of fetal membranes and responsiveness to inhaled nitric oxide in very preterm infants with hypoxic respiratory failure. J Pediatr. 2012;161(3):397-403.e1.

29. Semberova J, O'Donnell SM, Franta J, Miletin J. Inhaled nitric oxide in preterm infants with prolonged preterm rupture of the membranes: a case series. J Perinatol. 2015;35(4):304-306.

30. Chock VY, Van Meurs KP, Hintz SR, et al; NICHD Neonatal Research Network. Inhaled nitric oxide for preterm premature rupture of membranes, oligohydramnios, and pulmonary hypoplasia. Am J Perinatol. 2009;26(4):317-322.

31. Peliowski A, Finer NN, Etches PC, Tierney AJ, Ryan CA. Inhaled nitric oxide for premature infants after prolonged rupture of the membranes. J Pediatr. 1995;126(3):450-453.

32. Uga $N$, Ishii T, Kawase $Y$, Arai $H$, Tada H. Nitric oxide inhalation therapy in very low-birthweight 
infants with hypoplastic lung due to oligohydramnios. Pediatr Int. 2004;46(1):10-14.

33. Kilbride HW, Thibeault DW. Neonatal complications of preterm premature rupture of membranes. Pathophysiology and management. Clin Perinatol. 2001;28(4):761-785.

34. Geary C, Whitsett J. Inhaled nitric oxide for oligohydramnios-induced pulmonary hypoplasia: a report of two cases and review of the literature. J Perinatol. 2002;22(1):82-85.

35. Kabra NS, Kluckow MR, Powell J. Nitric oxide in preterm infant with pulmonary hypoplasia. Indian J Pediatr. 2004;71(5):427-429.

36. Williams O, Hutchings G, Debieve F, Debauche C. Contemporary neonatal outcome following rupture of membranes prior to 25 weeks with prolonged oligohydramnios. Early Hum Dev. 2009; 85(5):273-277.

37. Welzing L, Bagci S, Abramian A, Bartmann $P$, Berg C, Mueller A. CPAP combined with inhaled nitric oxide for treatment of lung hypoplasia and persistent foetal circulation due to prolonged PPROM. Early Hum Dev. 2011;87(1):17-20.

38. Lindner W, Pohlandt F, Grab D, Flock F. Acute respiratory failure and short-term outcome after premature rupture of the membranes and oligohydramnios before 20 weeks of gestation. J Pediatr. 2002;140(2):177-182.

39. Ball MK, Steinhorn RH. Inhaled nitric oxide for preterm infants: a Marksman's approach. J Pediatr. 2012;161(3):379-380.

40. Sokol GM, Konduri GG, Van Meurs KP. Inhaled nitric oxide therapy for pulmonary disorders of the term and preterm infant. Semin Perinatol. 2016;40 (6):356-369.

41. Kinsella JP, Steinhorn RH, Krishnan US, et al. Recommendations for the use of inhaled nitric oxide therapy in premature newborns with severe pulmonary hypertension. J Pediatr. 2016;170:312-314

42. Carey WA, Ellsworth MA, Harris MN. Inhaled nitric oxide use in the neonatal intensive care unit: rising costs and the need for a new research paradigm. JAMA Pediatr. 2016;170(7):639-640.

43. Spitzer AR, Ellsbury DL, Handler D, Clark RH. The Pediatrix BabySteps data warehouse and the Pediatrix QualitySteps improvement project system--tools for "meaningful use" in continuous quality improvement. Clin Perinatol. 2010;37(1): 49-70.

44. Tolia VN, Patrick SW, Bennett MM, et al. Increasing incidence of the neonatal abstinence syndrome in U.S. neonatal ICUs. N Engl J Med. 2015; 372(22):2118-2126.

45. Raju TN, Higgins RD, Stark AR, Leveno KJ. Optimizing care and outcome for late-preterm (near-term) infants: a summary of the workshop sponsored by the National Institute of Child Health and Human Development. Pediatrics. 2006;118 (3):1207-1214.

46. Laughon MM, Avant D, Tripathi N, et al. Drug labeling and exposure in neonates. JAMA Pediatr. 2014;168(2):130-136

47. Autmizguine J, Hornik CP, Benjamin DK Jr, et al; Best Pharmaceuticals for Children Act-Pediatric Trials Network Administrative Core Committee. Anaerobic antimicrobial therapy after necrotizing enterocolitis in VLBW infants. Pediatrics. 2015;135 (1):e117-e125

48. Trembath A, Hornik CP, Clark R, Smith PB, Daniels J, Laughon M; Best Pharmaceuticals for Children Act-Pediatric Trials Network. Comparative effectiveness of surfactant preparations in premature infants. J Pediatr. 2013;163(4):955-60.e1.

49. Olsen IE, Groveman SA, Lawson ML, Clark RH Zemel BS. New intrauterine growth curves based on United States data. Pediatrics. 2010;125(2):e214e224.

50. Aliaga $S$, Clark RH, Laughon $M$, et al. Changes in the incidence of candidiasis in neonatal intensive care units. Pediatrics. 2014:133(2):236-242.

51. Clark RH, Bloom BT, Spitzer AR, Gerstmann DR. Reported medication use in the neonatal intensive care unit: data from a large national data set. Pediatrics. 2006;117(6):1979-1987.

52. Clark RH, Bloom BT, Spitzer AR, Gerstmann DR. Empiric use of ampicillin and cefotaxime, compared with ampicillin and gentamicin, for neonates at risk for sepsis is associated with an increased risk of neonatal death. Pediatrics. 2006;117(1):67-74.

53. Rosenbaum PR, Rubin DB. The central role of the propensity score in observational studies for causal effects. Biometrika. 1983;70(1):41-55.

54. D'Agostino RB Jr. Propensity score methods for bias reduction in the comparison of a treatment to a non-randomized control group. Stat Med. 1998;17 (19):2265-2281.

55. Wacholder S, Silverman DT, McLaughlin JK, Mandel JS. Selection of controls in case-control studies. III. Design options. Am J Epidemiol. 1992; 135(9):1042-1050.

56. Lu B. Propensity score matching with time-dependent covariates. Biometrics. 2005;61 (3):721-728.

57. Austin PC. Balance diagnostics for comparing the distribution of baseline covariates between treatment groups in propensity-score matched samples. Stat Med. 2009;28(25):3083-3107.

58. Therneau TM, Grambsch PM. Modeling Survival Data: Extending the Cox Model. New York, NY: Spriger-Verlag; 2000.
59. Shah DM, Kluckow M. Early functional echocardiogram and inhaled nitric oxide: usefulness in managing neonates born following extreme preterm premature rupture of membranes (PPROM). J Paediatr Child Health. 2011;47(6): 340-345.

60. Keszler M. Guidelines for rational and cost-effective use of iNO therapy in term and preterm infants. J Clin Neonatol. 2012;1(2):59-63.

61. Chandrasekharan P, Kozielski R, Kumar VH, et al. Early use of inhaled nitric oxide in preterm infants: is there a rationale for selective approach? Am J Perinatol. 2017;34(5):428-440.

62. Cole FS, Alleyne C, Barks JD, et al. NIH consensus development conference statement: inhaled nitric-oxide therapy for premature infants. Pediatrics. 2011;127(2):363-369.

63. Peliowski A; Canadian Paediatric Society, Fetus and Newborn Committee. Inhaled nitric oxide use in newborns. Paediatr Child Health. 2012;17(2): 95-100.

64. Jackson J. Respiratory distress in the premature infant. In: Gleason C, Devaskar S, eds. Avery's Diseases of the Newborn. Philadelphia, PA: Elsevier/Saunders; 2012:642-645.

65. Evans N. Towards rational use of inhaled nitric oxide in preterm babies. Acta Paediatr. 2016;105 (2):121-122.

66. Abman $\mathrm{SH}$, Hansmann $\mathrm{G}$, Archer $\mathrm{SL}$, et al American Heart Association Council on Cardiopulmonary, Critical Care, Perioperative and Resuscitation; Council on Clinical Cardiology; Council on Cardiovascular Disease in the Young; Council on Cardiovascular Radiology and Intervention; Council on Cardiovascular Surgery and Anesthesia; and the American Thoracic Society. Pediatric pulmonary hypertension: guidelines from the American Heart Association and American Thoracic Society. Circulation. 2015;132(21):20372099.

67. de Waal K, Kluckow M. Prolonged rupture of membranes and pulmonary hypoplasia in very preterm infants: pathophysiology and guided treatment. J Pediatr. 2015:166(5):1113-1120.

68. Finer NN, Evans N. Inhaled nitric oxide for the preterm infant: evidence versus practice. Pediatrics. 2015;135(4):754-756.

69. Carey WA, Weaver AL, Mara KC, Clark RH Inhaled nitric oxide in extremely premature neonates with respiratory distress syndrome. Pediatrics. pii: e20173108.

70. Hamilton BE, Martin JA, Osterman MJ. Births: preliminary data for 2015. Natl Vital Stat Rep. 2016; 65(3):1-15. 